\title{
Muito além das virtudes epistêmicas. 0 historiador público em um mundo não linear ${ }^{1}$
}

\author{
Beyond the epistemic virtues. The public historian in a non-linear world
}

\author{
Fernando Nicolazzi \\ Universidade Federal do Rio Grande do Sul \\ fernando.nicolazzi@ufrgs.br
}

\begin{abstract}
Resumo: Este artigo tem por objetivo oferecer uma reflexão sobre as formas de atuação pública de historiadores e historiadoras no mundo contemporâneo, considerando a importância de se atentar para as demandas e expectativas que os diferentes públicos colocam sobre elas. A partir da análise de duas situações específicas envolvendo o historiador Leandro Karnal, o artigo argumenta que toda a reflexão que diz respeito à relação entre historiador e público é atravessada por uma dimensão ética que transcende os princípios puramente epistemológicos da disciplina e, por situar publicamente a atuação intelectual do historiador, assume ela própria uma dimensão política.
\end{abstract}

Palavras-chave: Historiador público; Públicos da história; Leandro Karnal.

\begin{abstract}
This article offers a reflection on the forms of historians public performance in the contemporary world, considering the importance of being attentive to the demands and expectations the different audiences have regarding this performance. From the analysis of two specific situations involving the historian Leandro Karnal, the article argues that all reflection on the relation between historian and his/her audience is crossed by an ethical dimension that transcends the purely epistemological principles of the discipline and, by publicly situating the historian's intellectual performance, it also takes on a political dimension.
\end{abstract}

Keywords: Public historian; Audiences of history; Leandro Karnal.

Recebido: Novembro 2017

Aprovado: Dezembro 2017

\footnotetext{
${ }^{1}$ Este artigo contou com financiamento do CNPq. Este ensaio é uma versão desenvolvida da conferência que proferi no âmbito dos Diálogos Contemporâneos do XXIX Simpósio Nacional de História, ocorrido em julho de 2017 em Brasília. Na ocasião, dividi a mesa sobre "Ética profissional e orientação política" com Arthur Assis e Sérgio da Mata, a quem agradeço pelo ótimo debate. Aquela versão foi igualmente apresentada no I Congresso de Ensino, Pesquisa e Extensão em História, em outubro do mesmo, no Departamento de História da Universidade Federal de Santa Maria. Agradeço à professora Beatriz Weber e aos demais organizadores do evento pela ótima acolhida e pela oportunidade de debater e lapidar melhor os argumentos aqui desenvolvidos.
} 
A que identidade, a que utilidade, a qual magistério pode pretender um ofício que se pensa tão técnico como os outros, tendo construído lentamente sua ética, suas regras e seu savoir-faire, mas que toda e qualquer pessoa, sob diferentes modalidades, parece poder praticá-lo?

Nicolas Offenstadt. ${ }^{2}$

\section{I.}

Parte considerável dos atuais debates em torno da prática historiográfica e da reflexão teórica sobre ela indicam uma "complexa conjunção entre epistemologia, ética profissional e política", situando o trabalho de historiadores e historiadoras diante de um contexto de crise que acaba por incidir diretamente sobre seu ambiente de atuação profissional. ${ }^{3}$ Porém, se tais debates emergem hoje como um convite irrecusável à reflexão, também carregam em si alguns riscos eminentes. O primeiro deles é o da referida reflexão se tornar, ao final, a imposição de um dogma. Em outras palavras, trata-se do perigo de se confundir aquilo que se apresenta como possibilidade de ser pensado na forma de um diálogo, com aquilo que acaba se transformando em uma estreita prescrição de trabalho, que normalmente se manifesta na forma de imperativos que procuram determinar o que é e como deve ser praticado o trabalho historiográfico. O sentido deste artigo ao enfrentar a mencionada conjunção será, portanto, o de tentar contornar o risco de fazer destas palavras uma proposição dogmática.

O segundo risco que se quer aqui evitar de forma mais enfática é o de transformar a reflexão sobre a conjunção entre ética profissional e orientação política, pensada a partir da relação entre os historiadores e seus públicos, em uma espécie de discurso esotérico a respeito de valores exclusivamente universais, ou seja, fundamentada em certos pressupostos que, em tese, valeriam para todo e qualquer indivíduo, independente das condições sociais, das

\footnotetext{
${ }^{2}$ OFFENSTADT, Nicolas. Histoires et historiens dans I'espace publique. In: GRANGER, Christophe (dir.). $\dot{A}$ quoi pensent les historiens? Faire de l'histoire au XXI siècle. Paris: Éditions Autrement, 2013, p. 80.

${ }^{3}$ Eis a formulação da proposta de um recente diálogo contemporâneo ocorrido no Simpósio Nacional de História da ANPUH, em julho de 2017: "conjunturas politicamente tensionadas são um constante desafio à noção algo ingênua de que, em história, a verdade só pode ser obtida quando buscada de maneira desinteressada e desapaixonada, sine ira et studio. A rejeição do ideal empirista de um cordão sanitário entre historiografia e política, e o concomitante rebaixamento das verdades históricas à condição de (no melhor dos casos) 'verdades situadas' abalaram fortemente o conceito tradicional de objetividade histórica. Curiosamente, entretanto, essa desvalorização dos potenciais cognitivos da historiografia não se estendeu aos padrões tradicionais de integridade intelectual. Muito pelo contrário, o que se verifica nos últimos anos é precisamente uma crescente sensibilização para as múltiplas interfaces entre história e ética. Além disso, o dever de dizer a verdade permanece sendo o imperativo ético fundamental da historiografia acadêmica, seja esta explicitamente engajada ou não. A proposta desta mesa é refletir sobre essa complexa conjunção entre epistemologia, ética profissional e política. Tensões e arranjos entre objetividade, integridade e engajamento serão abordados tanto de uma perspectiva teórica geral quanto por meio de estudos de casos recentes e pretéritos". O título dado à mesa foi "Ética profissional e orientação política na historiografia". Disponível
} <http://www.snh2017.anpuh.org/conteudo/view?ID_CONTEUDO=2308>. Acesso em: 29 out. 2017. 
definições espaciais e das situações temporais em que se encontra. Por essa mesma razão, não há neste texto a pretensão de amparar as considerações que serão feitas nas bases, talvez mais ilusórias que efetivas, de um consenso disciplinar, como se a disciplina da história pudesse existir apesar ou mesmo à revelia daqueles e daquelas que a praticam e, inclusive, das tensões e diferenças que os movem. Valendo-me livremente das proposições oferecidas por Pedro Telles da Silveira, trata-se de valorizar o dissenso como procedimento constitutivo do debate público no qual se pretende situar o conhecimento histórico, e não da defesa acirrada de seus postulados disciplinares como discurso de autoridade. ${ }^{4}$

Considerando, então, os dois riscos mencionados, proponho uma forma de abordagem das relações entre ética e engajamento político no campo da historiografia, particularmente em uma situação de crise social, a partir de um duplo encaminhamento: em primeiro lugar, considero a noção de ética profissional como uma categoria menos substantiva do que processual, ou seja, não como algo que se possui (segundo a expressão comumente usada de "ter ética") e sim como o exercício constante de "constituição de si" realizado pelo historiador enquanto historiador, remetendo às práticas de subjetivação que Michel Foucault estudou nos últimos anos de sua vida. Essa consideração inicial, embora mantenha uma forma de abordagem distinta, vem ao encontro das recentes propostas feitas por João Ohara para o estudo dos modos disciplinados de ser historiador no Brasil, pensadas a partir dos trabalhos de Herman Paul sobre as virtudes epistêmicas que caracterizam e definem a persona acadêmica (scholarly persona) dos praticantes do ofício. ${ }^{5}$

Isso significa compreender que a definição do que é ser historiador (ou historiadora) depende de um conjunto bastante complexo e variado de fatores que podem se referir tanto à fabricação de algo, naquele sentido indagado por Michel de Certeau ao se perguntar o que fabrica o historiador quando faz história, ${ }^{6}$ quanto aos processos de legitimação que frequentemente são assumidos pelos pares acadêmicos, de que a banca de tese ou o parecer técnico são das formas mais evidentes. Junto a esses dois fatores, é possível considerar ainda, como faz Ohara, que tal definição é igualmente dependente de um processo de construção subjetiva que implica na prática de algumas virtudes epistêmicas, morais e sociais. Para falarmos da modalidade disciplinada de historiador (ao que normalmente se atribui a qualidade de "historiador profissional"), é preciso considerar, então, que além dos diplomas e mecanismos disciplinares de reconhecimento, do domínio das técnicas metodológicas e dos protocolos teóricos que conformam a disciplina, são realizadas também algumas "técnicas de si" (utilizando o vocabulário foucaultiano) que não se justapõem necessariamente aos requisitos epistemológicos demandados pelas normas "internas" do ofício. Em outras palavras,

\footnotetext{
4 SILVEIRA, Pedro Telles da. Para além do consenso historiográfico: o giro ético-político e o dissenso na historiografia contemporânea. Texto não publicado, gentilmente cedido pelo autor, a quem agradeço.

5 OHARA, João Rodolfo Munhoz. The disciplined historian: "epistemic virtue", "scholarly persona", and practices of subjectivation. A proposal for the study of Brazilian professional historiography. In: Práticas da História. Journal on Theory, Historiography, and uses of the past, v. 1, n. 2, p. 39-56, 2016. Para a abordagem de Herman Paul, ver: PAUL, Herman. What is a scholarly persona? Ten theses on virtues, skills, and desires. In: History and Theory, n. 53, p. 348-371, 2014.

${ }^{6}$ CERTEAU, Michel de. L'écriture de I'histoire. Paris: Gallimard, 1975.
} 
falar em ética profissional equivale aqui a situar o discurso em um plano mais amplo do que o simples cumprimento das regras da disciplina, buscando compreender igualmente as demandas que são colocadas no âmbito dos diferentes espaços públicos da sociedade e as formas com que historiadores e historiadoras lidam com elas.

Disso resulta o segundo encaminhamento proposto: considero a noção de orientação política a partir dos modos de intervenção pública dos historiadores e historiadoras em um espaço que transcende os limites, por vezes demasiadamente restritos, da esfera acadêmicodisciplinar. Embora mantenha alguns pontos de contato, essa ideia não se justapõe plenamente à prática da chamada História Pública, campo bastante amplo e variado que tem contribuído de modo considerável para repensar os contornos de nosso ofício e sua legitimidade social. ${ }^{7}$ Minha proposta é, portanto, tentar refletir sobre a conjunção daquela construção ética realizada pelos historiadores no seu exercício profissional, pensada enquanto técnica de elaboração de uma persona acadêmica (e social), com as formas pelas quais tal construção se manifesta publicamente e responde a demandas públicas que nem sempre se esgotam em exigências puramente epistemológicas ou disciplinares. Em outras palavras, tratase de pensar a dimensão performativa da atuação historiográfica para além da história disciplinada, percebendo a atuação do seu praticante como, de fato, um historiador público.

Esta reflexão se insere, assim, dentro de um quadro mais vasto no qual se encontra em primeiro plano a preocupação em articular a percepção da crise política e cultural contemporânea com os possíveis caminhos que se abrem para a transformação dos espaços de saber no Brasil, sobretudo aqueles situados no âmbito da universidade pública. Dentro deste quadro, o repensar as condições para se (re)politizar a prática historiográfica assume aqui uma posição privilegiada. A hipótese que se levanta, dessa maneira, é a de que não basta que a reflexão epistemológica sobre o fazer histórico se concentre única e exclusivamente em seus postulados de produção, isto é, nos modos e princípios que orientam a construção do saber historiográfico. Creio que, sem desconsiderar estes postulados, a atenção deve igualmente ser voltada para os planos da circulação e da recepção do conhecimento produzido, pensando as formas de atuação social e intervenção pública de historiadores e historiadoras em nossa sociedade. Nesse sentido, a atenção à audiência merece um lugar particular no âmbito das discussões historiográficas, notadamente em um momento em que outras tantas narrativas disputam, algumas de forma claramente desonesta (porque pautadas por um ataque direto aos professores de história), uma posição no jogo enunciativo sobre o passado e também, principalmente, sobre o presente. Além disso, considerando que a realidade universitária brasileira se alterou substancialmente a partir de uma série de medidas que procuraram garantir um acesso relativamente mais democratizado às universidades, outras tantas demandas e expectativas em relação à história foram criadas e colocadas diante de seus

\footnotetext{
7 Para uma visão abrangente deste campo no Brasil, ver: SANTHIAGO, Ricardo. Duas palavras, muitos significados: alguns comentários sobre a história pública no Brasil. In: MAUAD, Ana Maria; ALMEIDA, Juniele Rabêlo de; SANTHIAGO, Ricardo (orgs.). História pública no Brasil. Sentidos e itinerários. São Paulo: Letra e Voz, 2016.
} 
praticantes, fazendo com que a consideração delas seja hoje parte fundamental e eticamente constituinte do próprio fazer historiográfico.

II.

Com o intuito de desenvolver essa proposta, vou me valer de um exemplo empírico que se concretiza a partir de duas situações singulares. A primeira situação ocorreu no Rio de Janeiro, em um domingo de maio de 2017. O imenso auditório contava com mais de 25 mil pessoas dispostas em cadeiras organizadas em inúmeras e longas fileiras. No centro do auditório, com imagem privilegiada para o palco, uma espécie de zona vip foi delimitada. Ali foram colocados sofás brancos e garçons servindo os convidados que, em elegantes trajes de festa, acompanhavam com mais ou menos interesse o evento que se passava diante deles, entre um e outro sorriso para as câmeras que filmavam tudo ali. Os autofalantes anunciaram, então, a principal atração da tarde, informando se tratar do "palestrante mais requisitado do Brasil, historiador e professor da Unicamp, [que] participa em programas de rádio e televisão nas principais emissoras do país" e, no exato momento em que o locutor proferia o costumeiro "com vocês agora...", entrava, em meio a um show de luzes e música tecno, com sonoros e efusivos aplausos do público, caminhando compassadamente no extenso palco montado para a celebração, o colega de métier Leandro Karnal. ${ }^{8}$

Era, sem dúvida, um dos momentos mais importantes da Hinode Rio Fest, evento que, se acreditarmos na proposta dos organizadores, ofereceu "dois dias de motivação, lançamentos de produtos, premiação de líderes, reconhecimentos e muito mais. Tudo para você aprender e se emocionar". ${ }^{9}$ O Grupo Hinode foi criado em 1988 por um casal de empreendedores de Barueri como empresa de vendas de produtos cosméticos. Tem nome inspirado na cultura japonesa, significando "o primeiro raio do sol nascente no primeiro dia do ano", e seu lema, "vencer é contagiante", parece inspirar verdadeiramente milhares de pessoas pelo mundo afora. Hoje, com fábrica própria e mais de 400 franquias espalhadas em diversos lugares, o grupo trabalha com o sistema de "marketing multinível", por meio do qual seus melhores consultores são premiados conforme a categoria de rendimento que atingem: a Diamante propicia um cruzeiro marítimo pela costa brasileira; a Imperial Two Stars oferece como recompensa uma viagem pelo Tahiti, um relógio Rolex e uma joia Tiffany; por fim, para aqueles mais bem-sucedidos que atingiram o nível Imperial Three Stars, um carro de luxo é dado como prêmio. As Hinode Fests são, portanto, momentos privilegiados onde tudo isso é evidenciado para aqueles e aquelas que fazem parte do grupo, transformando as vitórias pessoais em grandes conquistas coletivas.

\footnotetext{
8 O vídeo com a íntegra da palestra está disponível na página de You Tube Território Conhecimento. Disponível em: <https://www.youtube.com/watch?v=55GXRWQI8ds\&t=2090s>. Acesso em: 29 out. 2017.

9 Informações sobre a edição de 2017 e de anos anteriores estão disponíveis em: <http://hinodefest.grupohinode.com.br/>. Acesso em: 29 out. 2017.
} 
Foi, então, para uma plateia de consultores do Grupo Hinode que Karnal, o "historiador mais pop do país" segundo o ranking de historiadores da Revista Veja e que é acompanhado predominantemente por "eleitores de esquerda", ${ }^{10}$ ofereceu uma cuidadosa fala de exatamente uma hora, misturando, como tem sido sua consciente e declarada estratégia, piadas e citações eruditas para atrair o público para obras e autores "relevantes". ${ }^{11}$ o tema da palestra, que citava entre outros autores Jean-Paul Sartre, Epicuro e Gandhi, era uma "pergunta incômoda": "eu sou feliz?", e a pretensão do historiador foi, em suas próprias palavras, "transformar a vida" daqueles que ali o ouviam. Tratava-se, para não haver dúvidas, da fala de um professor universitário que se dedica há mais de 30 anos ao estudo de assuntos que estão "nos livros e na vida"; portanto, seguindo as considerações feitas anteriormente, tratava-se da intervenção pública de um historiador disciplinado e é dessa maneira que esta fala será aqui analisada.

Não há dúvidas: Karnal é realmente brilhante no que faz. Para uma plateia que estima os padrões de sucesso representados pela categoria Imperial Three Stars, que acompanha curiosa os movimentos daqueles distintos colegas que, por conta da sua conquistada distinção, podem adentrar o setor reservado de sofás brancos e bandejas fartas no centro do auditório, o orador oferece a motivação necessária e o entusiasmo requerido para atingir as três estrelas da categoria. Lembra, inclusive, para uma audiência predominantemente cristã, que a própria etimologia da palavra entusiasmo garante que o entusiasta é aquele que está "cheio de deus" (aplausos da plateia). Obviamente, não vem ao caso discutir as minúcias sobre a qual ou a quais deuses aquela etimologia grega (e pagã) se refere: o momento, evidentemente, não pede chatices eruditas. Por outro lado, as formas de motivação propícias para a ocasião requerem do palestrante que assuma igualmente, como ele mesmo adverte, "a função chata do filósofo": assim, situando-se em um contexto de crise social, considerado por ele como um dos momentos mais difíceis da história do Brasil procede com a crítica ao individualismo crescente. O que chama a atenção, contudo, é que correlato a tal crítica não parece haver o direcionamento da atenção da plateia para a instância social, mas sim tão somente o elogio da dimensão coletiva da empresa. Afinal, é só caminhando juntos e em sintonia que consultor e empresa podem crescer e gozar da emoção contagiante da vitória. Por isso o historiador se faz conselheiro moral, enfatizando a importância de se prestar atenção no outro, dando a este outro um nome singular: "olhem para o rosto das pessoas - diz Karnal enfaticamente - olhem para o rosto dos clientes, o rosto de quem está comprando". Num passe retórico, então, a alteridade se converte em simples relação comercial: a empatia solidária se transforma, assim, em estratégia de venda.

Contra o individualismo, portanto, não é requerido um cuidado social, mas sim uma atenção primordialmente mercantil. E se, como garante aquele homem sábio e cativante andando de um lado para o outro do palco, "o rosto humano é um livro poderoso", certamente seu poder reside no fato dele revelar quais os desejos de consumo que se escondem por detrás daqueles olhos, daquele nariz, daquelas bochechas dos clientes que devem ser

\footnotetext{
${ }^{10}$ Entrevista com Leandro Karnal. Revista Veja, 05 abr. 2017, p. 15.

${ }^{11}$ Idem.
} 
cuidadosamente olhados, analisados, desvendados em seus mais íntimos desejos de consumo. Por isso, o sucesso depende desse olhar cuidadoso, mas também de certo controle do tempo: um dos principais erros das pessoas, segundo o historiador, é se preocupar em demasia "com o momento seguinte". O consultor bem-sucedido será aquele que melhor aproveitar (melhor controlar, portanto) o seu próprio presente: "ao tentar uma venda, ao ler um livro, ao namorar, ao conversar com seu filho, ao fazer qualquer coisa importante na sua vida [...] não fique pensando no que vem depois [...] entreguem-se, entreguem-se a isso" (aplausos da plateia). É possível notar que a ordem das atividades não é ali feita por mero acaso; ela está de acordo com a ocasião: para aquela plateia específica, em primeiro lugar está a venda, depois podem vir o livro, o namoro, o filho ou qualquer outra coisa tão importante quanto a venda.

Não há como deixar de perceber que, junto à crítica ao individualismo, há um princípio meritocrático nestes conselhos que, ao fim e ao cabo, transformam-se pela habilidade retórica do orador na própria valorização do indivíduo, pelo menos daquele que, segundo ele, tem méritos. Sua própria conduta serve como exemplo e parâmetro para isso. Karnal narra para sua audiência todo o esforço pessoal que realizou ao longo dos anos para chegar onde se encontra. Durante seus estudos, diz ter evitado excesso de festas, recusado maconha e que, por isso, "não pegava ninguém" (risos da plateia). Além disso, sempre mirou alto em seus próprios valores e objetivos, que significavam tornar-se um "profissional de excelência": queria ser Alexandre, o Grande, não o médio, tampouco o pequeno, brinca o historiador cativando o auditório (mais risos da plateia). O esforço próprio, a despeito das condições sociais, é o que conta em última instância. Obviamente, outras minúcias como o fato dele ter se tornado doutor em uma universidade pública, com bolsa de uma agência pública de financiamento não são relevantes para manter a coerência do relato, pelo menos para aquela plateia em particular. Não há sorte no mundo, diz ele, ela é "o nome que o vagabundo dá ao esforço que ele não fez". Por outro lado, aquele que, como o orador, "sócio majoritário" da sua própria existência, acorda sempre às 4 horas da manhã e que tem claro quais os valores e metas a perseguir, certamente trilhará de modo seguro o caminho para o sucesso e, portanto, para a felicidade, não deixando margem para o destino ou para o azar. Os obstáculos, quando se impõem, como a atual crise social mencionada, não são outra coisa se não o excesso de perspectivas abertas diante de si. Eis a "pista histórica" dada pelo historiador-conselheiro a partir de seu próprio campo de saber: a experiência de crise descortina novas e empolgantes expectativas. É a crise, por fim, o que separa "quem é bom de quem é ruim, o amador do profissional, quem veio ao mundo a trabalho ou a passeio". Não há como deixar de lembrar da frase mobilizada em maio de 2016 por Michel Temer, ainda como presidente interino, sobre a situação social no Brasil: "não fale em crise, trabalhe!".12

Toda a performance é permeada pelo tom imperativo da fala suave e serena do orador: façam!, evitem!, vejam!, queiram!, conheçam!. Além disso, frases de efeito produzem a

12 Ver: <http://www1.folha.uol.com.br/poder/2016/05/1771899-empresario-espalha-frase-citada-portemer-em-outdoors-de-ms.shtml>. Acesso em: 29 out. 2017. 
motivação desejada: "eu sou a transformação que eu quero ver no mundo", "o tempo é hoje, é agora". Em uma hora exata de palestra, ricos ensinamentos morais são acompanhados por momentos de prazer, com a intenção de comover e mover para a ação. Vemos e ouvimos, portanto, o uso habilidoso e eficaz dos três princípios retóricos clássicos: docere, delectare, movere. ${ }^{13}$ Ao final da fala, o fechamento impecável um pouco antes da selfie sobre o palco: "agora vai começar o primeiro dia do resto da vida de vocês" (aplausos e gritos efusivos da plateia). Fim da primeira situação.

A segunda situação, que será mais brevemente mencionada, servirá apenas para colocar em perspectiva a primeira. Ela ocorreu dois anos antes, em maio de 2015, em um ambiente diferente, num outro contexto e com plateia distinta. Foi uma aula inaugural proferida em uma universidade pública, para o Programa de Pós-Graduação em História da Universidade Federal de Uberlândia. Ou seja, Karnal estava diante dos seus pares acadêmicos, e suas preocupações não eram as condições da felicidade humana, mas sim as perspectivas mais prosaicas para o ser historiador no mundo contemporâneo. De todo modo, tratava-se igualmente da atuação de um historiador disciplinado. ${ }^{14}$

Como a ocasião e o ambiente fazem o orador, a primeira frase citada para seus próprios colegas vem de ninguém menos que Karl Marx, tirada do manifesto escrito em 1848 e que serviu para Marshall Berman dar título ao seu conhecido livro Tudo que é sólido desmancha no ar. Em seguida, o ponto de ligação com a obra de Zygmunt Bauman sobre a liquidez do mundo contemporâneo é estabelecido. Karnal aproveita a oportunidade para ressaltar a importância de se ler obras que são incontornáveis para a historiografia, como o próprio Manifesto comunista, sem o conhecimento das quais, segundo ele, enfático e decisivo, não se pode ser historiador. Estamos, portanto, dentro de limites disciplinares bem definidos e compartilhados entre orador e auditório, os quais estabelecem certas práticas como fundamentais para sua plena realização, a leitura do cânone sendo uma delas. Como aconselha o historiador, "quem não tem compulsão pela leitura está na carreira errada. Vá vender Amway, Avon, Jequiti [...] porque dá dinheiro, é simpático e não precisa ler nada além de catálogo" (risos da plateia). Cabe indicar que Amway, Avon e Jequiti são empresas com formas de atuação muito similares as do Grupo Hinode: vendem produtos cosméticos por meio de estratégias motivacionais voltadas para seus consultores, os mesmos para quem, dali a dois anos, Karnal estará oferecendo seus conselhos de vida, sem obviamente sugerir sua suposta inaptidão para a leitura que agora Ihe serve como recurso humorístico.

Momentos depois, na mesma aula sobre ser historiador no século XXI, oferece alguns comentários sobre o que chama das três grandes teologias do século XX: a primeira delas, o "empreendedorismo" (teologia que, não custa lembrar, levou uma ex-costureira e um exmetalúrgico a criarem o Grupo Hinode), definido por ele como "a fórmula mágica mais imbecil já criada por um capitalismo que já teve dias melhores"; a segunda é a "teologia da

\footnotetext{
13 Sobre isso, remeto à: TEIXEIRA, Felipe Charbel. Uma construção de fatos e palavras: Cícero e a concepção retórica da história. Varia História, v. 24, n. 40, p. 551-568, 2008.

14 A aula intitulada "Tempo, historiografia e mundo líquido", está disponível em: <https://www.youtube.com/watch?v=cqYpFwki1CA>. Acesso em: 29 out. 2017.
} 
prosperidade", ou seja, aquilo pelo quê 25 mil pessoas o ouvirão dois anos depois; por fim, a terceira, também vinculada às duas anteriores, é a "autoajuda", isto é, o discurso de motivação pessoal para se encontrar a felicidade no mundo ou, em outras palavras, o discurso que procura responder à singela pergunta: "eu sou feliz?". Para fundamentar seus argumentos, Karnal cita o livro $O$ segredo, de Rhonda Byrne, como exemplo da última destas teologias, criticando o mote da autora segundo o qual tudo aquilo que você pensa se torna realidade. Para o historiador, que hoje motiva as pessoas assegurando serem elas mesmas "a transformação que querem ver no mundo", trata-se, naquele momento, de uma construção própria de crianças em fase pré-cognitiva e de esquizofrênicos (risos contidos na plateia).

Mas o tema geral da aula não foi esquecido e Karnal trata dele nos momentos finais de sua fala. Seu enfoque destaca a importância do historiador contemporâneo pensar no "grande público", assim como Marc Bloch defendia a dimensão lúdica da história. Ressalta a importância comercial de Laurentino Gomes e condena o oportunismo desonesto de Leandro Narloch. Estabelece uma dicotomia entre as obras, como a de Laurentino, que oferecem uma linguagem mais acessível e, para ele, esteticamente mais cuidadosa, e um debate especializado em algum simpósio da ANPUH onde, por exemplo, apenas "oito especialistas" tratam da historiografia da escravidão, falando apenas para eles mesmos e valendo-se, nas suas palavras, da "feiura da linguagem acadêmica". ${ }^{15}$ Ser historiador no século XXI significa, portanto, atentar seriamente para sua relação com o público e tentar, sempre que possível, valer-se de uma forma de linguagem que cause beleza e provoque prazer, atraindo com isso um número cada vez maior de leitores. Para ele, esta é uma exigência natural do mercado de livros, embora "nós", historiadores, "não podemos estar inseridos na lógica do mercado". A aula é, então, encerrada com um elenco de exemplos de historiadores que, para o gosto de Karnal, escreveram de forma esteticamente mais aceitável. ${ }^{16} \mathrm{Fim}$ da segunda situação.

\section{III.}

Em um primeiro momento, o que chama a atenção nestas duas situações é a notável capacidade de adaptação que Leandro Karnal possui diante de auditórios tão variados. Se a atuação em ambas parece obedecer ao mesmo princípio, ou seja, o do historiador como bom conselheiro (mostrando os caminhos da felicidade em um caso e, no outro, os dilemas da prática historiográfica e como enfrentá-los), os procedimentos utilizados são sensivelmente distintos. Embora todo o gestual seja muito próximo, os termos usados e a atitude assumida se diferenciam. Em 2015, a evidente auto-ironia em relação a si mesmo, no caso de um

\footnotetext{
15 Não custa atentar para um fato importante: em junho de 2017, João José Reis, historiador da escravidão, foi agraciado com o prêmio Machado de Assis da Academia Brasileira de Letras pelo conjunto de sua obra.

16 O elenco passa por Michel de Certeau, Carl Schorske, Natalie Zemon Davis, Edward Palmer Thompson, Cristopher Hill. Entre os brasileiros, é significativo que a única menção feita seja a Evaldo Cabral de Mello que, a rigor, não é historiador de formação universitária.
} 
praticante da historiografia disciplinada (interesse supostamente de apenas 8 especialistas), cede lugar em 2017 para o elogio do esforço pessoal (daquele que acorda às 4 horas da manhã para perseguir suas metas). Aquele que buscava exemplos de conduta discursiva (a lista dos historiadores que bem escrevem), converte-se ele mesmo no próprio exemplo de conduta moral (o homem bem-sucedido). Além disso, o que antes era motivo do comentário jocoso, dois anos depois se tornará o objeto principal da sua fala e, inclusive, o responsável financeiro por ela.

Obviamente, não seria o caso de cobrar de Karnal que apresentasse para os vendedores do Grupo Hinode, a obra daquele que teorizou sobre o fetichismo da mercadoria ou que assegurou haver um espectro comunista rondando a Europa. Afinal, o intuito era produzir motivação e não gerar pânico em 25 mil pessoas num auditório lotado. Da mesma forma, seria tarefa talvez inócua oferecer estratégias de venda e de sucesso comercial, ou mesmo o segredo da felicidade, para estudantes da área de humanas que, ou querem destruir a exploração capitalista mundial, ou já leram muita literatura para acreditar que basta perseguir metas individuais para ser feliz em uma sociedade. Cabe, porém, atentar para o fato: nos dois casos, o auditório fez o orador.

O que gostaria de destacar com isso é o fato de que, no processo consciente e complexo da construção deste modelo multifacetado de persona acadêmica, estamos em um plano muito além das virtudes puramente epistêmicas, um plano que, inclusive, embaralha um pouco as sugestões feitas por Herman Paul em suas teses sobre virtudes, habilidades e desejos acadêmicos. ${ }^{17}$ Pois se a persona do historiador, entendida pelo autor holandês como "modelos de individualidade acadêmica" (models of scholarly selfhood), não se confunde com máscaras que são vestidas conforme a ocasião, mas, pelo contrário, se constitui a partir de certas disposições que nunca são desvinculadas do indivíduo, como compreender tamanha flexibilidade de posicionamento de Karnal nas duas situações descritas? Qual deles deve ser levado em consideração: aquele que subestima a capacidade de leitura de vendedores de cosméticos ou aquele que tenta ensiná-los o caminho de sucesso para as vendas e, com isso, para a felicidade?

Creio que para se pensar as modalidades de intervenção pública dos historiadores, então, há de se considerar igualmente as formas pelas quais se dá a intervenção do público sobre os historiadores. Ou seja, há uma dimensão da legitimidade do trabalho intelectual, constitutiva da persona acadêmica, que, pelo menos nos casos aqui tratados, independe apenas das virtudes epistêmicas daquele que o realiza e está amparada predominantemente nas virtudes que o auditório parece estabelecer como demanda. Assim, este argumento traz para o primeiro plano o papel dos públicos na conformação da ética profissional e também dos modos de orientação política assumidos e praticados por historiadores e historiadoras. Em alguns casos, o bom intelectual é aquele que desempenha uma função pública mais reativa, ou seja, é aquele que simplesmente reage a um ambiente e se apresenta como garantidor das

\footnotetext{
${ }^{17}$ PAUL, Herman. What is a schlarly... Op. cit.
} 
certezas preestabelecidas; a palestra motivacional organizada pelo Grupo Hinode me parece um exemplo disso: não há qualquer questionamento em relação a nada do que estava ali em jogo, sobretudo, em relação à justaposição fácil entre sucesso de vendas e felicidade pessoal. Era exatamente isso o que aquela audiência parecia querer e esperava ouvir. Em outros casos, todavia, ele pode assumir o papel de quem incita a dúvida, suspende as familiaridades e desconstrói o que aparece como evidência; a fala questionadora da disciplina para um programa de pós-graduação ilustra essa perspectiva: seus ouvintes são levados a problematizar sua própria prática, buscando outros caminhos para praticá-la. Em certa medida, a expectativa do público foi igualmente atendida.

Não estou com isso estabelecendo um juízo de valor sobre um ou outro caso, como se houvesse uma escala de qualidade moral entre eles, mas sim sugerindo que correlata à pergunta sempre constante sobre a função social do historiador está a indagação sobre para que público ele está falando ou escrevendo, ou seja, sobre a demanda social pelo historiador. Dito de outro modo, isso significa considerar que as duas perguntas sobre o que historiadores têm para oferecer para a sociedade e sobre o que a sociedade produz de expectativa em relação a eles andam juntas, mesmo que nem sempre sejam coincidentes. É justamente neste espaço performático entre a produção e a recepção do conhecimento, entre a escrita e a leitura (ou entre a fala e a audiência), que a dimensão ética transparece na atuação pública dos historiadores. Caso, como normalmente se sugere, o dever de "dizer a verdade" permaneça sendo o imperativo ético fundamental da historiografia acadêmica, creio ser igualmente fundamental considerar não apenas quem diz tal verdade e como o faz, mas também para quem ela é dita, o que se faz com ela e como ela funciona em determinado contexto social.

Em outras palavras, é possível considerar a dimensão da ética profissional na historiografia como uma qualidade performativa que articula os historiadores e historiadoras com suas diferentes audiências, constituindo seu modo de atuação e intervenção no espaço público e, por isso mesmo, assumindo uma dimensão eminentemente política. No caso aqui mencionado, as duas situações mostram com nitidez a complexidade envolvida no trato destas questões. Por um lado, a fala elaborada em 2015 para o auditório de um programa de pósgraduação incentiva a busca por uma nova modalidade de escrita historiográfica e, dessa maneira, incita o constante pensar sobre a prática disciplinar da história, trazendo em seu bojo a reflexão sobre o próprio lugar onde é praticada, isto é, a universidade pública. Insere-se, obviamente, dentro dos modos de exercício de um poder disciplinar que produz, nesse sentido, sujeitos disciplinados, mas a partir de um viés que permite nele mesmo o questionamento de um modelo de disciplina supostamente fechada em si mesma, criando brechas para sua transformação e abertura para públicos mais amplos. Todas estas questões conformam, dessa maneira, o próprio ethos do historiador contemporâneo apresentado nesta oportunidade. Como sugere João Ohara, "pela produção de subjetividades, os praticantes de certas disciplinas acadêmicas são disciplinados. Eles aprendem conceitos e leem certos textos considerados importantes pelo seu campo, mas aprendem também a ser historiadores [...] Daí 
em diante, não apenas têm adquirido habilidades cognitivas específicas, mas também referências não-epistêmicas em relação às quais eles se posicionam como historiadores política, ética e esteticamente". ${ }^{18}$

Por outro lado, a palestra motivacional oferecida aos consultores de venda do Grupo Hinode em 2017 se insere em outra lógica e pode ser ligada, inclusive, a uma forma de racionalidade mais ampla que é ela própria amparada em outras formas de relação de poder. Aqui, a equação entre sucesso de vendas e mérito individual é colocada como condição imprescindível para se chegar à felicidade que, mesmo sem ser plenamente enunciado como tal, é o objeto desejado por aquela audiência específica. Como afirmam Pierre Dardot e Christian Laval, "a vontade de realização pessoal, o projeto que se quer leva a cabo, a motivação que anima o 'colaborador' da empresa, enfim, o desejo com todos os nomes que se queira dar a ele é o alvo do novo poder". Por conta disso, prosseguem os autores, "o ser desejante não é apenas o ponto de aplicação desse poder; ele é o substituto dos dispositivos de direção das condutas. Porque o efeito procurado pelas novas práticas de fabricação e gestão do novo sujeito é fazer com que o indivíduo trabalhe para a empresa como se trabalhasse para si mesmo e, assim, eliminar qualquer sentimento de alienação e até mesmo qualquer distância entre o indivíduo e a empresa que o emprega". ${ }^{19}$

Tem-se, portanto, duas formas de relação díspares que, à primeira vista, parecem contraditórias entre si: no primeiro caso, a relação entre estudantes de história e universidade pública mediada pela reflexão sobre o estatuto da historiografia enquanto disciplina acadêmica; no segundo, a relação entre consultores e a empresa onde atuam mediada pelo incentivo à venda e ao mérito individual. Porém, é viável colocar ainda outra pergunta talvez mais constrangedora: em um mundo de relações sociais e de construções individuais flexíveis, seria tal disparidade realmente uma contradição ou, pelo contrário, seria ela a própria racionalidade que move este mundo? Em outras palavras, a atuação deste mesmo historiador público nos dois ambientes, por mais que motivada por intenções tão visivelmente distintas, não parece sugerir uma proximidade de fundo entre um e outro espaço, ou seja, entre a universidade e a empresa?

\section{IV.}

Não são poucas as intervenções, desde abordagens mais fundamentadas até comentários rápidos em redes sociais, que vêm apontando para o processo acelerado de transformações que aproximam a universidade da empresa, seja no plano do gerenciamento institucional, seja no âmbito das formas de avaliação acadêmica. ${ }^{20}$ Todavia, como este assunto

\footnotetext{
18 OHARA, João Rodolfo Munhoz. The disciplined historian... Op. cit., p. 49-50.

19 DARDOT, Pierre; LAVAL, Christian. A nova razão do mundo. Ensaio sobre a sociedade neoliberal. São Paulo: Boitempo, p. 327.

20 Para alguns poucos exemplos, ver: LEHER, Roberto; VITTORIA, Paolo; MOTTA, Vânia. Educação e mercantilização em meio à tormenta político-econômica do Brasil. In: Germinal. Marxismo e educação em
} 
demanda mais espaço e tempo do que me é aqui possível, o foco das considerações feitas será voltado especificamente para a forma de atuação de Leandro Karnal nos dois casos relatados. Assim, creio não ser de todo equivocado situar a construção da persona acadêmica deste historiador público no plano daquilo que Dardot e Laval chamaram de "nova razão do mundo", ou seja, o quadro mais amplo de racionalidade que fundamenta a sociedade neoliberal contemporânea. ${ }^{21}$

Retomando a proposta de João Ohara, segundo a qual a formação da identidade intelectual daquele ou daquela que pratica história é feita a partir de um "maquinário de subjetivação" (machinery of subjectivation), é possível considerar com ele ainda que "o lugar social da história é, então, o ponto por meio do qual é possível abarcar este maquinário em ação - onde se tenta moldar o seu eu acadêmico (scholarly self) por meio da referência a um repertório de personas acadêmicas que lhe estão disponíveis em dada situação histórica". ${ }^{22} \mathrm{O}$ que Dardot e Laval oferecem, nesse sentido, é uma perspectiva plausível para pensarmos o que a atual situação histórica oferece como disponibilidade para a construção de si daquele historiador em particular. Assim, considero fundamental para este argumento a colocação feita pelos autores franceses de que a dimensão normativa da razão neoliberal "muda até o indivíduo, que é instado a conceber a si mesmo e a comportar-se como uma empresa". ${ }^{23}$ Em outras palavras, o neoliberalismo se estabelece como uma "norma" a partir da qual a produção de sujeitos tem lugar, colocando o mercado como espaço privilegiado para isso e a concorrência como modus operandi principal.

Assim, o sujeito neoliberal é também um sujeito instado a todo momento a criar formas de atuação, ou de "governo de si" (como preferem os autores a partir de uma chave de leitura foucaultiana), que transformam cada indivíduo em um possível empreendedor: este "é um ser dotado de espírito comercial, à procura de qualquer oportunidade de lucro que se apresente e ele possa aproveitar, graças às informações que ele tem e os outros não". Com isso, concluem de forma enfática: "o mercado é um processo de formação de si". ${ }^{24}$ Considerando, então, que todo este processo de subjetivação se dá através de uma lógica concorrencial que parece valorizar antes os méritos próprios da concorrência (e dos concorrentes) em detrimento das condições sociais na qual ela se dá, todo participante desta lógica é convocado a valorizar-se a si mesmo como um capital passível de rendimento: o indivíduo se torna, então, um "capital humano".

\footnotetext{
debate, v. 9, n. 1, p. 14-24, 2017; ARAUJO, Valdei Lopes de. O regime de autonomia avaliativo no Sistema Nacional de Pós-Graduação e o futuro das relações entre historiografia, ensino e experiência da história. Anos 90, v. 23, n. 44, p. 85-110, 2016; LAVAL, Christian. Les nouvelles usines du savoir du capitalisme universitaire. Revue du MAUSS, n. 33, p. 173-184, 2009/1; LORENZ, Chris. Sobre el economicismo y el canibalismo académico. Disponível <https://www.academia.edu/15488434/Sobre_el_economicismo_y_el_canibalismo_acad\%C3\%A9mico>. Acesso em: 29 out. 2017.

${ }^{21}$ DARDOT, Pierre; LAVAL, Christian. A nova razão do mundo... Op. cit.

22 OHARA, João Rodolfo Munhoz. The disciplined historian... Op. cit., p. 50.

${ }^{23}$ Op. cit., p. 16.

${ }^{24}$ Ibidem, p. 145.
} 
O historiador público, enquanto conselheiro (disciplinar ou motivacional), está não apenas oferecendo sábios conselhos, mas também entregando um produto (seja ele remunerado ou não). Além disso, está entregando-se ele mesmo como um produto que pode servir de modelo de conduta para aqueles que o ouvem com atenção ou simplesmente consomem o que tem a dizer. No site de internet Kratos Klio, usado como instrumento de divulgação dos serviços oferecidos por Leandro Karnal como palestrante, o tema da "difusão do conhecimento" no mundo contemporâneo é colocado em primeiro plano, encarado antes como caminho para se atingir uma meta do que a própria meta em si. ${ }^{25} \mathrm{E}$ ali é elencado todo um rol de possibilidades de conteúdo aos interessados que quiserem ou puderem contratar seus serviços: ética, corrupção, empreendedorismo, liderança, o mal, o ódio, planejamento estratégico, protagonismo, gestão de mudanças, relação entre magistrados e servidores, vida bem-sucedida, vaidade, conhecimento, mundo líquido e outros temas aparecem como possibilidades de atuação do historiador-palestrante.

O que me parece interessante constatar é a aparente desconexão entre o campo propriamente disciplinar da história e o mundo dos serviços motivacionais oferecidos. Entre os temas elencados não estavam (pelo menos no momento em que foi consultado) aqueles que poderíamos considerar como próprios da especialização historiográfica do palestrante. Cronistas coloniais, representações religiosas no século XVI, fontes historiográficas, ensino da história, por exemplo, não aparecem listados. Possivelmente, um limite ético foi ali estabelecido: tais temas não são conteúdos oferecidos nas formas de serviços remunerados, sobretudo se considerarmos que são temas que interessam notadamente o público universitário. Mas é possível que haja ainda uma justificável razão comercial nisso, afinal, mesmo sem ter dados disponíveis para afirmar com mais fundamento, dificilmente uma empresa gostaria de motivar seus funcionários com histórias sobre cronistas do século XVII. De todo modo, a referida desconexão de campos não implica por parte de Karnal em uma recusa ou negação do seu estatuto social enquanto historiador acadêmico: a descrição do seu currículo constante no site demonstra isso. Afinal, mesmo que sem grande apelo para o mercado, o ser professor universitário ainda lhe oferece um capital simbólico considerável dentro de nosso sistema intelectual. Resta saber até quando isso continuará sendo necessário para os fins propostos.

Por isso penso ser fundamental analisar suas formas de atuação em conjunto e de modo comparativo, pois elas são antes complementares que excludentes. A fala de 2015 está em plena sintonia com a fala de 2017, embora o conteúdo da primeira possa contradizer o da segunda. Entre uma e outra, vemos o profissionalismo de um ator social que deve se fazer cada vez mais flexível num mercado de trabalho que é, em sua dinâmica própria, um espaço de competição e de concorrência onde (supostamente) apenas os mais aptos têm condições (ou méritos) de ser bem-sucedidos. E uma das estratégias fundamentais para se jogar este jogo é estar atento às demandas que os diferentes públicos colocam para seu jogador,

25 Ver: http://www.kratosklio.com.br/. A consulta foi realizada em outubro de 2017. O site passou recentemente por uma considerável reforma, cujas alterações me escapam. 
tornando, neste caso, o historiador um sujeito plenamente adaptado e adaptável aos variados ambientes em que atua. No fundo, não se trata apenas da capacidade de se fazer ouvir por diferentes auditórios (a busca por aquela linguagem mais "bonita" ou "acessível" da aula de 2015), mas, no limite, trata-se da disponibilidade de dizer a tais auditórios o que eles querem escutar ou pagam para ouvir, mesmo que a risada de uma determinada plateia tenha que ser conquistada às custas daquilo que outra plateia representa. Afinal, o velho (e discutível) mote do mercado ainda parece ser um princípio pertinente nestes casos: o cliente tem sempre razão.

\section{V.}

O exemplo de atuação do historiador público aqui analisado coloca para a reflexão sobre o estatuto social da historiografia, considerado a partir das suas variadas formas de produção, circulação e recepção, uma série de questionamentos que atravessam não apenas o campo disciplinar da história, mas avançam em temas que dizem respeito à ética e à dimensão política dos saberes socialmente constituídos. Creio que se tornam particularmente sensíveis justamente em um momento em que as relações entre historiadores, historiadoras e seus públicos são situadas diante de um contexto de crise que põe em risco os princípios mais básicos para a existência de formas de educação democráticas e plurais: a liberdade de ensinar e as condições materiais para isso. Os impasses resultantes dessa crise já foram oportunamente destacados por Francisco Gouvêa de Sousa, Géssica Guimarães Gaio e Thiago Lima Nicodemo, num artigo em que é problematizada a abertura do saber histórico para auditórios mais amplos, a partir da ideia de democratização dos discursos em que o falar para certas plateias cede espaço ao falar com determinados públicos. E os autores têm plena razão ao colocar isso dentro de uma realidade universitária popular e marcada por demandas e expectativas extremamente variadas. ${ }^{26}$

Diante disso, a posição de Leandro Karnal da forma como foi aqui analisada tensiona a reflexão, tornando mais complexo, pertinente e urgente o pensamento proposto por Francisco, Géssica e Thiago. Pois se uma das condições para o enfrentamento e para a resistência em relação à crise atual passa pela atenção efetiva aos diferentes auditórios dos historiadores e historiadoras, quais os limites ou precauções podem ou devem ser colocados para isso? Em outras palavras, como realizar o gesto de abertura do saber histórico, vinculando-o ao processo de democratização dos seus espaços de produção e circulação (a universidade pública sendo um deles), a partir de uma "nova razão do mundo" que tende justamente, por um lado, a atacar frontalmente a existência de tais espaços (a universidade pública é tornada um fardo econômico diante de exigências neoliberais de eficácia empresarial) e, por outro, a anular os

\footnotetext{
${ }^{26}$ SOUSA, Francisco Gouvêa de; GAIO, Géssica Guimarães; NICODEMO, Thiago Lima. Uma lágrima sobre a cicatriz: o desmonte da universidade pública como desafio à reflexão histórica (\#UERJResiste). Revista Maracanan, Rio de Janeiro, n. 17, p. 71-87, jul./dez. 2017.
} 
efeitos políticos das práticas democráticas almejadas (a despolitização da política realizada pelo neoliberalismo conduz à "desdemocratização" da democraciaa ${ }^{27}$ )?

Os limites deste artigo e os objetivos aqui propostos não permitem avançar mais nestas questões, que envolveriam também analisar onde e de que maneira a lógica neoliberal incide sobre as práticas cotidianas dos historiadores e historiadoras, particularmente aqueles que atuam em ambientes universitários, com suas lógicas próprias de gerenciamento de "recursos humanos" e recursos financeiros, seus métodos de arregimentação profissional e seus processos avaliativos de desempenho. Creio, contudo, que o argumento sobre as possibilidades de atuação do historiador público no mundo contemporâneo já está colocado, com todos os impasses e desafios que isso impõe à própria reflexão, salientando a importância de se acrescentar aos tópicos desta reflexão o lugar e o papel dos públicos da historiografia na definição dos seus critérios de legitimidade social e, em alguns casos, disciplinar, incidindo notadamente nas relações entre ética profissional e orientação política.

Para finalizar, gostaria de lembrar que, há já algum tempo, quando nem disciplina historiográfica existia ainda, um jovem grego ouvia atenta e emocionadamente as narrativas daquele que posteriormente Cícero nomeou como o "pai da história". Isso fez o jovem tornarse igualmente um historiador e, quem sabe, o inaugurador da prole daquele pai, quando resolveu oferecer ao mundo o seu próprio relato sobre os feitos e fatos da guerra do Peloponeso. Como se sabe, Tucídides, no que talvez tenha sido o primeiro conflito de gerações de que se tem conhecimento na historiografia ocidental, criticou a figura paterna e todos aqueles que, como Heródoto, "compuseram visando ao que é mais atraente para o auditório de preferência ao que é verdadeiro". ${ }^{28}$ Com isso, iniciou toda uma fortuna crítica que jogou figura de Heródoto, durante séculos, para um campo marginal ao saber histórico e à própria relação mantida com a verdade, além de ter estabelecido uma discutível dicotomia entre o prazer da narrativa e a utilidade do saber narrado. ${ }^{29}$ Hoje certamente a relação entre a atração do público e a enunciação das verdades se coloca de forma distinta, tornando legitimamente viável que os historiadores se abram para auditórios cada vez mais amplos e impondo outros desafios para a reflexão em um mundo que, mesmo assumindo uma nova (des)razão, não é linear.

\footnotetext{
27 "Se, ao contrário, sustentarmos que a democracia repousa sobre a soberania de um povo, o que aparece então é que, enquanto doutrina, o neoliberalismo é, não acidentalmente, mas essencialmente, um antidemocratismo". DARDOT, Pierre; LAVAL, Christian. A nova razão do mundo... Op. cit., p. 384.

28 TUCÍDIDES. Guerra do Peloponeso, I, XXI. Utilizo a edição estabelecida por Jacqueline de Romilly e traduzida para o português por Anna Lia Amaral de Almeida Prado. História da Guerra do Peloponeso. Livro I. São Paulo: Martins Fontes, 1999, p. 29.

29 Sobre a relação dos historiadores antigos com seus públicos, ver: MOMIGLIANO, Arnaldo. Les historiens du monde classique et leurs publics: quelques suggestions. In: Problèmes d'historiographie ancienne et moderne. Paris: Gallimard, 1983. Para considerações rápidas sobre a fortuna crítica a respeito de Heródoto, ver: HARTOG, François. O nome de Heródoto. In: O espelho de Heródoto. Ensaio sobre a representação do outro. Belo Horizonte: Editora da UFMG, 1999.
} 
Fernando Nicolazzi: Professor do Departamento de História e do Programa de Pós-graduação em História da Universidade Federal do Rio Grande do Sul (UFRGS) e do Mestrado Profissional em Ensino de História - PROFHISTORIA. Possui graduação em História pela Universidade Federal do Paraná (UFPR); mestrado e doutorado em História pela UFRGS. É pesquisador do Laboratório de Estudos sobre os Usos Políticos do Passado (LUPPA-UFRGS) e pesquisadorcolaborador do Núcleo de Estudos em História da Historiografia e Modernidade (NEHM-UFOP). Seus principais temas de pesquisa são: Teoria da História; Historiografia moderna; Historiografia brasileira. 